\title{
Study on Compensation Control of STATCOM Based on MMC
}

\author{
Yan $\mathrm{Xie}^{1, \mathrm{a}}, \mathrm{Mu} \mathrm{LI}^{2}$ \\ ${ }^{1}$ School of Electrical and Electronic Engineering, Wuhan Polytechnic University, Wuhan 430023, China \\ ${ }^{2}$ Wuhan Nari Limited Liability Company of State Grid Electric Power Research Institute, Wuhan 430074, China
}

\begin{abstract}
This paper introduced modular multi-level converter (MMC), which could enhance the voltage and power level by sub-converter modules in series and was easy to extend to any level of output. Its structure and working mechanism were described. By analyzing the energy transfer performance of STATCOM based on MMC working conditions in the compensation, a comprehensive compensation control strategy was proposed based on direct current control mode. By analyzing the higher harmonic components circulation generated by the inconsistencies in the threephase upper and lower arm voltage, a loop control strategy is proposed for the suppression of the circulation in the arms of the M-STATCOM. The simulation results show the strategy has a better tracking precision and response speed for the compensation control.
\end{abstract}

\section{Introduction}

With the development of power electronics technology, a variety of high-power switching devices was used widely. In the high-voltage high-power application fields, the demand for advanced power electronic devices has become increasingly urgent, such as in the field of power transmission and distribution, voltage source converter(VSC) has be widely used. VSC can have various forms of topology, and now commonly used the two-level VSC and three-level VSC in practice. There are the main problems for two-level VSC, which are static voltage balance, dynamic voltage balance and electromagnetic interference (EMI) caused by the insulated gate bipolar transistor (IGBT) series, and excessive switching losses caused by the high switching frequency. For multi-level voltage source converter, common topologies include diode clamped, capacitor clamped and cascaded H-bridge type.

From the point of industrial production and demand for services, it is essential that the main inverter circuit is strictly modular structure. In 2002, a new topology of modular multi-level VSC is proposed by Germany Bundeswehr Munich University. The new modular multilevel VSC (MMC) satisfies the modular functional requirements, and it will capacitance and switching device as a whole to build a sub-module, to enhance the voltage and power level by sub-converter modules in series, easy to extend to any level of output, and it can be used to reduce switching loss and improve transmission efficiency with low harmonic distortion and lower switching frequency.

With all the above its advantages, the study on MMC is become a hot research. In this paper the structure and

\footnotetext{
a Yan Xie: limimimm@163.com
}

working mechanism of the MMC are described, and an MMC bridge armbands flow control strategy is given to achieve the effective suppression of the circulation of the high-frequency component and verify the effect of the control.

\section{Structure and working principle of MMC}

Three-phase MMC converter structure is shown in Figure 1(a). It has a modular structure. Each phase includes upper and lower bridge, and each bridge consists of $n$ sub-modules and current limiting reactor $\mathrm{L}$ in series. Udc is the DC side voltage. In order to maintain a constant DC output voltage, at any time into each phase of MMC is equal to the total number of sub-modules. So each phase of the MMC sub-module has $2 \mathrm{n}$, the number of output level is $n+1$. The sub-module structure is shown in Figure 1(b). Each sub-module structure is the same. It includes: T1 and T2 (insulated gate bipolar transistors, IGBT), D1 and D2 (diodes for the continued flow) and C (the submodule capacitor). $\mathrm{u}_{\mathrm{C}}$ is the voltage of the sub-module capacitor $\mathrm{C}$.

By controlling the switch IGBT T1 and T2, it can make the capacitor $\mathrm{C}$ into or removed from the bridge, and the corresponding output voltage $\mathrm{u}_{\mathrm{SM}}$ is equal to $\mathrm{u}_{\mathrm{c}}$ or 0 .The work state of new modular multi-level converter (MMC) is changed by controlling its sub-modules (Fig.1). According to current direction of the bridge arm, switches T1 and T2 of sub-module are controlled on or off, and the capacitor $\mathrm{C}$ is achieve to be charged, discharged, or bypass, so the sub-module output voltage $\mathrm{u}_{\mathrm{sm}}$ varies between zero and $\mathrm{u}_{\mathrm{c}}$. When the operating switches $\mathrm{T} 1$ and $\mathrm{T} 2$, it is equivalent to a DC power input 
or removal from the bridge. Through balancing the submodule's capacitor voltage, it is considered the capacitor voltage as the voltage source $u_{c}$.
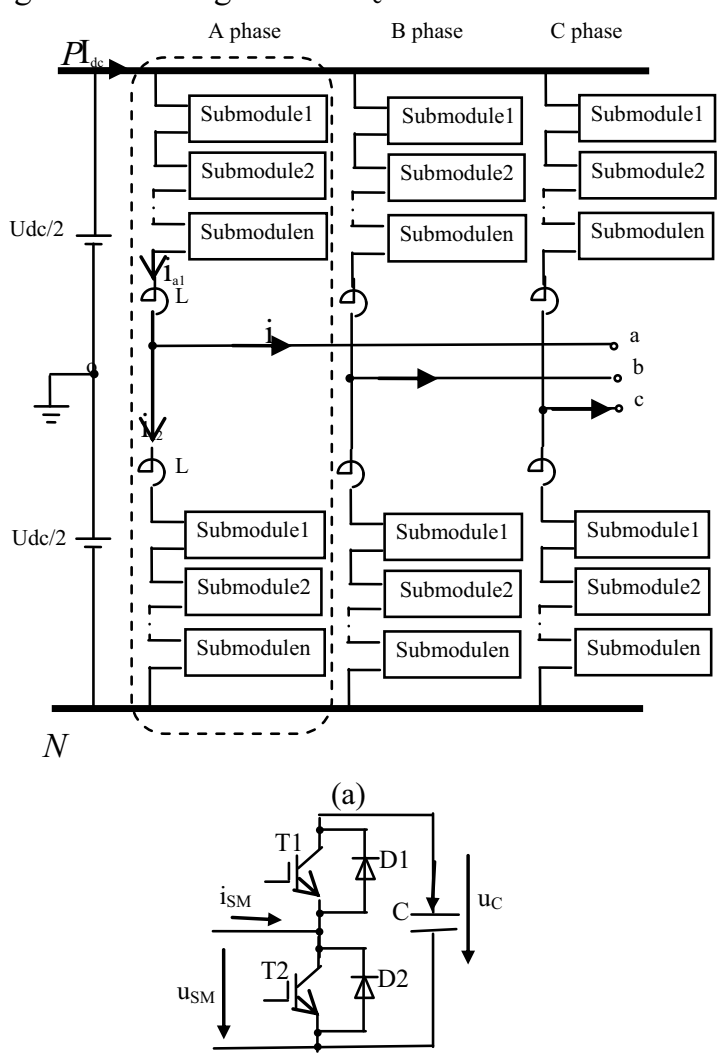

(b)

Figure 1. The circuit structure of MMC system (a) and MMC sub-module (b)

MMC used as STATCOM in China is at an early research stage, and there is a lot of research work needed. Existing studies show that the three-phase M-STATCOM system (i.e. the STATCOM system based on MMC) is at run time, there will be a high-order harmonic component circulation in the bridge arm. The circulation will not have any impact for external AC system, but it will increase requirements for the flow capacity of the MMC bridge arm power module. Therefore, in order to reduce the MMC power module current stress requirements, it is necessary on the effective circulation suppressed.

\section{Control of STATCOM based on MMC}

When the M-STATCOM operates on comprehensive compensation for the negative sequence current according to the load changing, the equivalent circuit is shown in Figure 2.

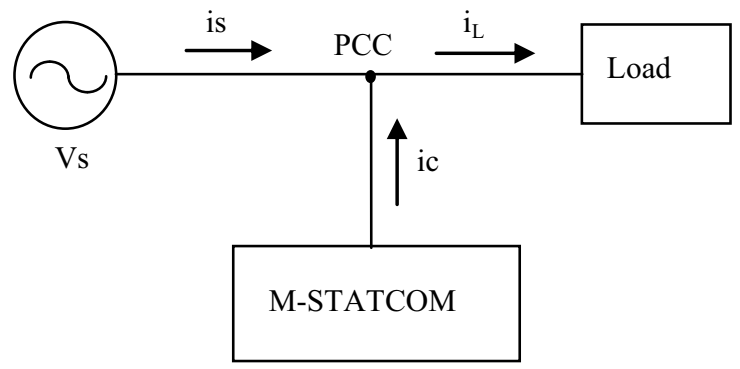

Figure 2. Equivalent circuit diagram of the system when MSTATCOM working in unbalance compensation condition

\subsection{Unbalance compensation control}

When the M-STATCOM working in imbalance compensation control state, it can be seen as a the ideal current source parallel with the grid based on the direct current control theory. The control objective is the output current of M-STATCOM system being fast-tracked to compensate for the desired harmonics, negative sequence and reactive current components of uneven load side and ensuring the current supplied by the grid containing only the fundamental positive sequence active current component. By M-STATCOM system compensation, the grid current and voltage are in same phase and symmetrical three-phase. The direct current control strategy can meet the requirements for fast dynamic response speed and small steady-state error.

Figure 3 shows the control block diagram of the MSTATCOM system unbalance compensation, which uses d-q model decoupling control method based on the synchronous rotating coordinate system.
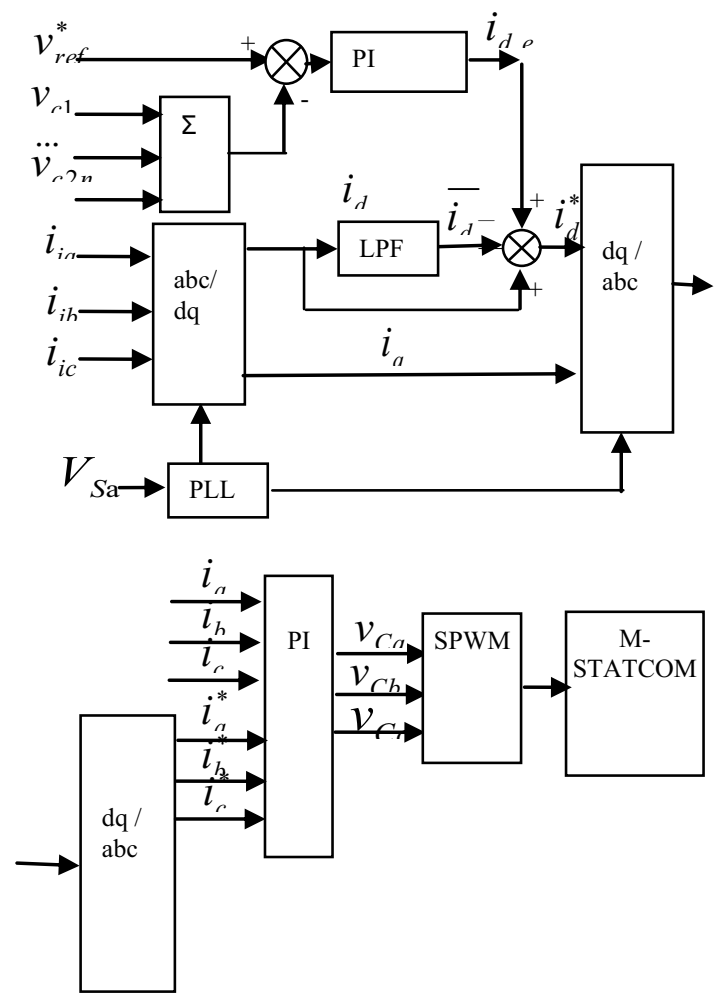

Figure. 3 The control block diagram of M-STATCOM system working in the integrated compensation

\subsection{Circulation control}

These higher harmonic components circulation is essentially due to the inconsistencies in the three-phase upper and lower arm voltage, and they flows between MMC three-phase bridge arm balanced in order to achieve the energy between each phase leg.

Figure 4 shows M-STATCOM single-phase circuit and its equivalent circuit with three-phase inductive load phase. Based on the idea of balance each phase leg 
voltage, an MMC bridge armbands flow control strategy is given to achieve the effective suppression of the circulation of the high-frequency component and verify the effect of the control.

According to their working principle, there are:

$$
\begin{gathered}
V_{a^{\prime} o}=V_{p o}-V_{p} \\
V_{a^{\prime \prime o}}=-V_{o n}+V_{n}
\end{gathered}
$$

And so

$$
V_{a^{\prime} a^{\prime \prime}}=V_{a^{\prime} o}-V_{a^{\prime \prime} o}=V_{p o}+V_{o n}-V_{p}-V_{n}
$$

To a point in figure 2 , there are:

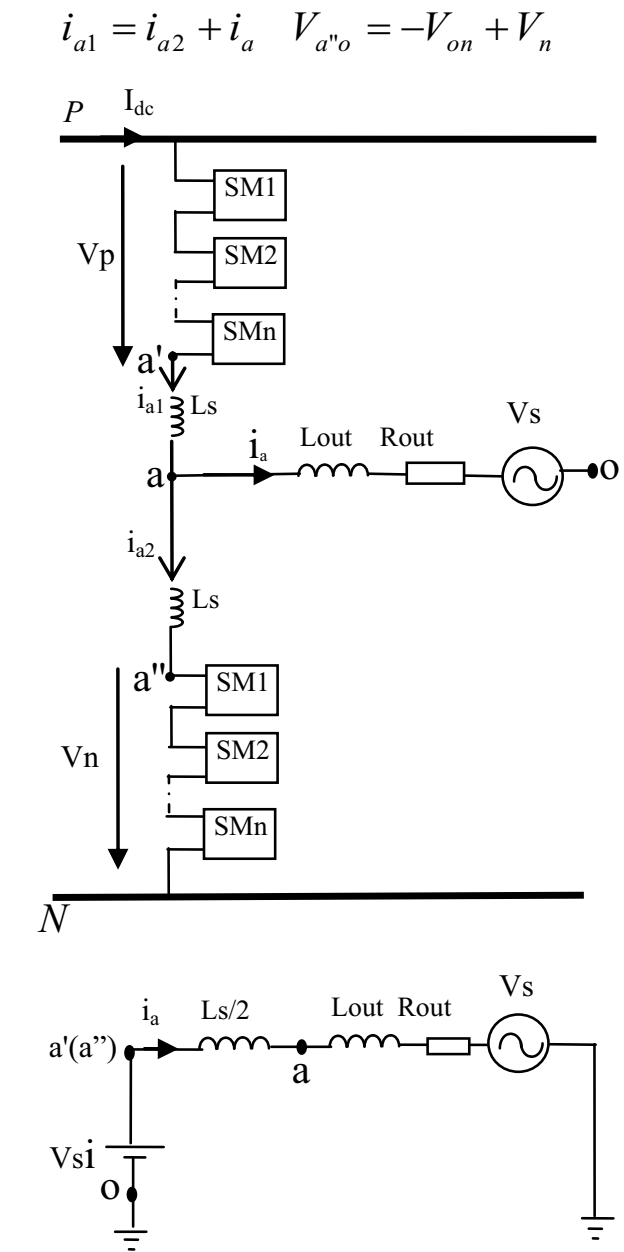

Figure 4. M-STÄTCOM single-phase circuit and its equivalent circuit diagram

Let a phase bridge arm in circulation are as follows:

$$
i_{Z}=\frac{i_{a 1}+i_{a 2}}{2}
$$

So the upper and lower arms of the current are:

$$
i_{a 1}=i_{Z}+\frac{i_{a}}{2} \text {, and } i_{a 2}=i_{Z}-\frac{i_{a}}{2}
$$

The corresponding voltage and current relationship is as follows:

$$
V_{a^{\prime} a}=V_{a a^{\prime \prime}}=-\frac{V_{a^{\prime} a^{\prime \prime}}}{2}
$$

Take the reference value of upper-arm power module output the control voltage and the lower-arm power module output control voltage, respectively are:

$$
\begin{gathered}
V_{p a^{\prime}}^{*}=-V_{a o}^{*}-\frac{V_{a^{\prime} a^{\prime \prime}}^{*}}{2}+V_{p o} \\
V_{a^{\prime \prime} n}^{*}=V_{a o}^{*}-\frac{V_{a^{\prime} a^{\prime \prime}}^{*}}{2}+V_{o n}
\end{gathered}
$$

Therefore, the control block diagram of the circulation controller can be gotten as figure 5 .

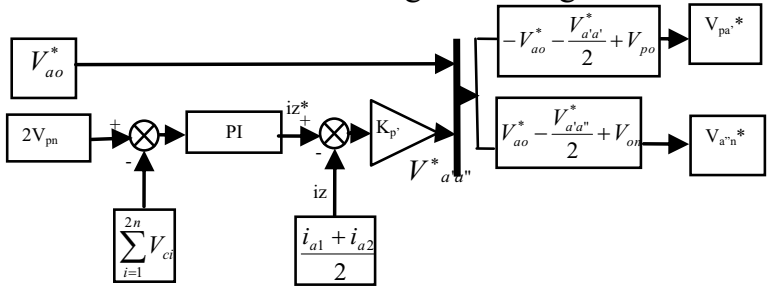

Figure 5. Single-phase M-STATCOM devices circulation control relationship diagram

\section{Simulation results}

According to the control strategy (Figure 3), the grid system voltage is $10 \mathrm{kV}$, and a resistive inductive load $\mathrm{Z}=10+\mathrm{j} 0.63 \Omega$ is connected between the $\mathrm{B}$ and $\mathrm{C}$ phases. The second and third harmonic currents are superimposed on the load side, and it makes the load unbalance and containing harmonic current component. In $\mathrm{t} 1(=0.1 \mathrm{~s})$ time, M-STATCOM system has been put in to achieve integrated compensation for the grid negative sequence harmonics and reactive. For compensation control system, the PI control parameters of controlling the DC-side voltage value is taken as : $\mathrm{Kp}=2, \mathrm{Ki}=5$, and PI control parameters of controlling AC current value is taken as $: \mathrm{Kp}=800, \mathrm{Ki}=1$.

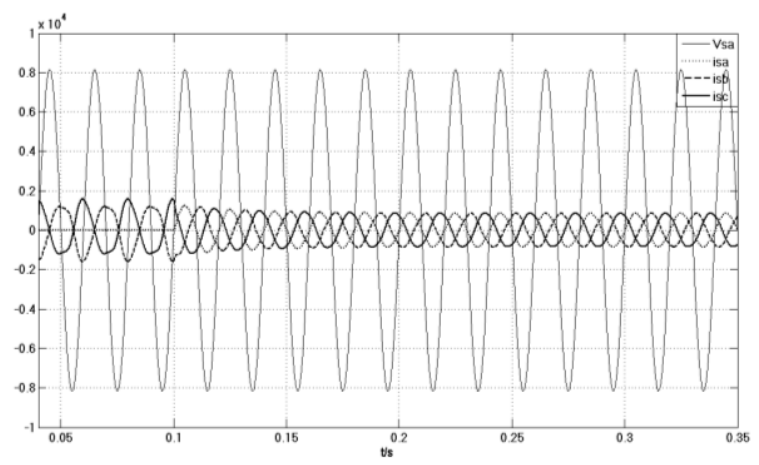

(a) A phase voltage and three-phase current waveforms

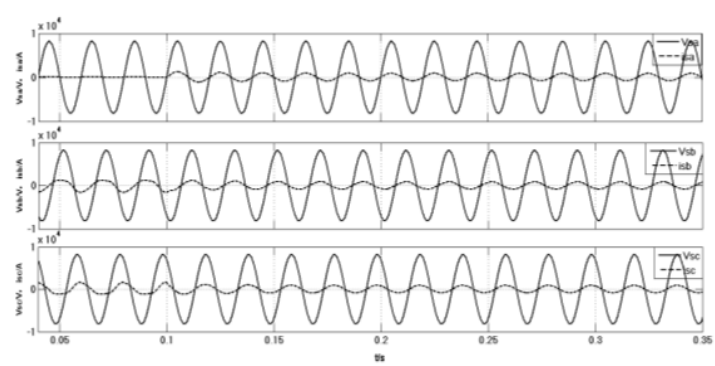

(b) Three phase voltages and three phase corresponding currents waveforms 


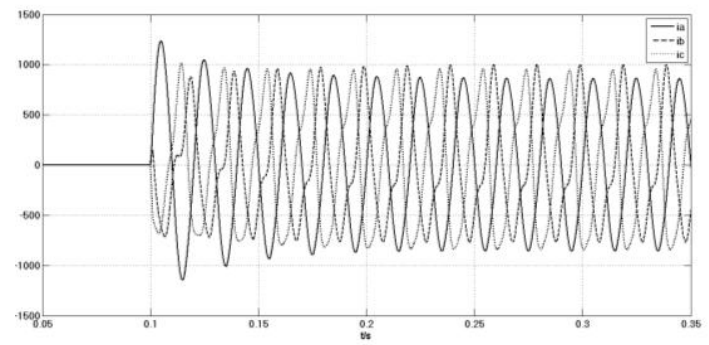

(c) M-STATCOM three-phase bridge arm output current waveforms

Figure 6. The simulation waveform of M-STATCOM system working in the current imbalance compensation

From figure 6(a), it show that the output current of the grid exist serious distortion due to load imbalances and low order harmonic currents, and the voltage and the output current exist phase difference due to the presence of the reactive load current.

In $\mathrm{t} 1, \mathrm{M}-\mathrm{STATCOM}$ device has been put in to the grid, and the grid three-phase output current waveform has been improving rapidly. The current total harmonic distortion rate decreased rapidly, the three-phase output current waveform close to the ideal symmetrical threephase sine wave, and its phase have been corrected to achieve unity power factor output of the grid control(Fig.6(b)).Compensating for the unbalanced load currents imbalance, its output currents are unbalanced (Fig.6(c)).

According to the loop control strategy (Figure 5), PI regulator control parameters of per phase DC bus regulator control is taken as: $\mathrm{Kp}=0.001, \mathrm{Ki}=0.01, \mathrm{Kp}{ }^{\prime}=$ 1000. This circulation suppressor is in operation at $\mathrm{t} 2$ ( $\mathrm{t} 2$ $=0.2 \mathrm{~s}$ ), and the current waveforms are as shown in Figure 7.

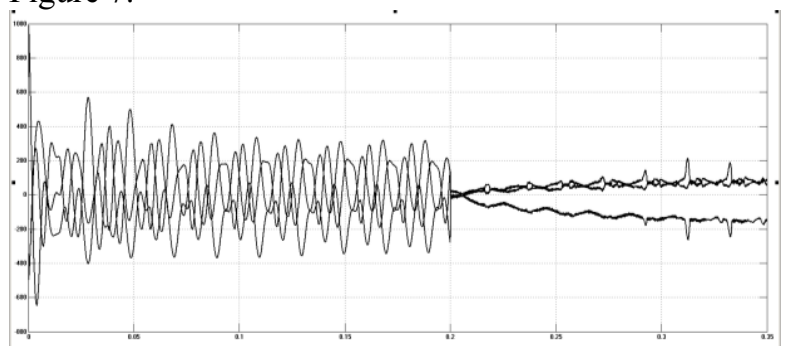

Figure 7. Three-phase M-STATCOM circulation suppression current simulation waveform

\section{Conclusion}

Recently, a modular multi-level converter (MMC) has been proposed and widely studied. So its structure and working principle has been described in detail. MMC used as STATCOM in China is at an early research stage. By analyzing the energy transfer performance of STATCOM based on MMC, this paper studied compensation control theory in complex conditions. To obtain compensation control response speed faster and better compensation effect, a comprehensive compensation control strategy was proposed based on direct current control mode. By analyzing the higher harmonic components circulation generated by the inconsistencies in the three-phase upper and lower arm voltage, a loop control strategy is proposed for the suppression of the circulation in the arms of the MSTATCOM. It can not only help to reduce the working current of the switching device of the sub-module, and can also reduce the power loss of the M-STATCOM system. The simulation results show the strategy has a better tracking precision and response speed for the control.

\section{References}

1. Veenstra M., Rufer, A. Control of a hybrid asymmetric multi-level inverter for competitive medium-voltage industrial drives. IEEE IAS Conf. Rec. 190-197(2003).

2. G.J.Ding, M.Ding, G.F.Tang, Z.Y. He: Submodule capacitance parameter and voltage balancing scheme ofa new multilevel VSC modular $[\mathrm{J}]$. Proceedings of the CSEE, 29 (30): 1-6 (in Chinese)(2009).

3. Q.R.Tu, Z.Xu, X.Zheng, M.Y.Guan, Mechanism Analysis on the Circulating Current in Modular Multi level Converter Based HVDC[J]. High Voltage Engineering, 36 (2): 547-552(2010).

4. Q.R.Tu, Z.Xu, M.Y.Guan, X.Zheng, J.Zhang. Design of circulating current suppressing controllers for modular multilevel converter[J]. Automat ion of Electric Power Systems, 34 (18): 57-61(2010).

5. S.S.Wang, X.X.Zhou, G.F.Tang, Z.Y.He, L.T.Teng, H.L.Bao. Analysis of sub module over current caused by DC pole-to-pole fault in modular multilevel converter HVDC system[J]. Proceedings of the CSEE,31 (1): 1-7(in Chinese)(2011). 